\title{
The Indianapolis Motor Speedway
}

Timothy Brunnemer, Novelis Corporation, USA

James R. Buffington, Indiana State University, USA

Jeffrey S. Harper, Indiana State University, USA

\begin{abstract}
This case study is intended to illustrate the issues surrounding planning and implementation of an enterprise system in a large organization with disparate business functions, with particular emphasis on application implementation, best practices, and IT investment decisions. It is recommended for either undergraduate- or graduate-level course work.
\end{abstract}

\section{INTRODUCTION}

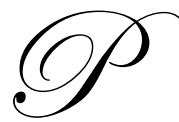

at Hayes' first day at the Indianapolis Motor Speedway (IMS) was the same day in 1993 that NASCAR teams participated in the first open test at the track. Prior to 1993, the Indianapolis 500 was the only race event that was hosted at the Speedway. While only a single event, the actual race and the preceding qualifying events occupied the entire month of May every year. The NASCAR testing would be a defining point of expansion and change for the Speedway. Pat Hayes, now in her role as Contract Administration Manager, has seen the Indianapolis Motor Speedway grow, with the addition of Formula One racing, from staging one race each year to three. She has also seen the number of employees rise from fifty to over 300 . Once located behind the museum at the track site, the business unit of the Speedway is now located in a three-story office building in front of the track, where they are now running out of office space. The Speedway as a business continues to expand today, and the coordination of this growth of operations has been successfully facilitated by their information systems staff.

\section{BRIEF HISTORY}

The Indianapolis Motor Speedway is known as the "Racing Capital of the World." Located in Speedway, Indiana, a town residing within the city limits of Indianapolis, Indiana, the track has been the home of the nation's premier racing event since 1911. The Indianapolis 500-Mile Race is an American tradition held every Memorial Day. The track was built in 1909. Two years later, the five-hundred-mile race was held for the first time after the owners abandoned smaller races and focused on promoting a major event. The first 500 race attracted an estimated 80,000 spectators. Since then, the race has become known as "The Greatest Spectacle in Racing" due to the event attendance and the audience from radio and television. The Speedway now has a permanent seating capacity of over 250,000 people, making the two and a half mile track the largest and highest-capacity racing facility in the world (“Indianapolis 500," 2007).

Survival and growth have always been concerns to the Speedway. The original track was made of crushed stone and tar. The first races held at the track were very dangerous, due in large part to the combination of this unstable surface and high speeds. Soon, the owners covered the track with over three million paving bricks, from which "The Brickyard" nickname is derived. The race continued through World War I and the Great Depression. It was at this time that increasing speeds of the racecars forced the track to be repaved again - this time with tarmac. During World War II, the Speedway was abandoned due to the cancellation of the race and a ban on all auto racing. In need of repair and investment, the Speedway was destined to become a housing development at the end of the war. It was at this time that the track was purchased by Terre Haute, Indiana, businessman Tony Hulman in 1945, at the urging of former race winner Wilbur Shaw ("The Hulman Family," 2007). This transfer of ownership proved to be a turning point in the growth and revitalization of the track and the race. 
Hulman \& Co. Tony Hulman was a successful businessman who had grown his family business, Hulman \& Company, to national recognition with Clabber Girl Baking Powder as the centerpiece product. Clabber Girl grew to be the top-selling baking powder in the United States due to his promotional efforts that began in the 1930s. At the time of the Great Depression, Hulman was able to grow the business by selling door-to-door across the country. Ten years later, the success of the business allowed him to purchase the Speedway for an estimated price of $\$ 750,000$. Through investment in major renovations and repairs, the race was restarted in 1946 after the four-year ban during World War II. Since that time, the Indianapolis Motor Speedway has enjoyed continued growth and expansion of operations. The Clabber Girl business continues today and is the top-selling baking powder in the country ("History of the...," 2007).

Today, the Speedway is host to three premier racing events. In addition to the "Indianapolis 500" of the IRL IndyCar series, the track hosts the NASCAR "Allstate 400 at The Brickyard" and the Formula One "United States Grand Prix" each year. Besides the race events, the 18-hole golf course known as "Brickyard Crossing," situated inside the oval, hosts PGA Senior Tour events. Also located within the Speedway oval, the current IMS Hall of Fame Museum, established in 1975, is recognized as one of the top museums dedicated to automobiles and auto racing. All of these businesses are housed under the Hulman \& Company umbrella.

When one thinks of the Indianapolis Motor Speedway as a business, you may be quick to judge it as "just a racetrack." However, the Speedway is actually a group of many, small individual businesses necessary to support daily operations and race events. This partial list includes Tickets, Food \& Beverage, Sales, Marketing, Retail, Credentials, and a Hospital, (see Figure 1). Compared to traditional businesses, the Speedway is a unique organization. Operations aside from the race track include merchandising, a hotel, a museum, and an 18-hole professional golf course.

All of these operations are components of the Indianapolis Motor Speedway, which is just one part of a privately held company (see figure 1). Hulman \& Company also includes a Food Services division (Clabber Girl) and an award-winning video production division (IMS Productions). IMS Productions is a media production company that specializes in live sports, documentaries, and event programming. The addition of race events and the creation of a new racing series (Indy Racing League) in the 1990s accelerated of this growth of IMS and its partner, Hulman \& Company.

Information Systems. When Pat Hayes started to work for the IMS Accounting department in 1993, information systems support was limited and business functions were supported by high maintenance applications. Since then, the organization has continually updated its information systems in an attempt to keep up with the rapid growth of the Speedway. Even so, staff members continue to request more functionality in computing capabilities. In particular, the need for customization of business applications and faster communication continues to be a major concern.

As Hulman and Company and the Speedway grew, each individual business was operating with separate databases and separate business procedures. This led to problems with data integrity and data redundancy. The business had also grown to include 100 servers and close to 600 desktop and laptop personal computers. By 2003, ten lines of business operated within the Speedway, each with its own database and accounting procedures. Customer entries would be unique to each functional area of the Speedway, which required the IS department to manually compile and merge data for organizational reporting.

All business operations and accounting functions experienced limitations due to the multiple sources of data. Within Pat Hayes' department and necessitated by Sales and Marketing, the added issue of communication and coordination was restricting the service IMS could offer customers. These issues can be addressed through customer relationship management. One problem encountered because of communication difficulties was that occasionally IMS double-booked hospitality suites to corporate customers. The booking of hospitality suites was a manual ledger activity by one person, which required communication with multiple sales staff. Another communications difficulty allowed sales contracts to be extended to customers with unpaid accounts. A third difficulty centered on free promotions. For example, corporate customers could contact multiple sales staff, 
receiving multiple sets of free tickets without the knowledge of the Sales Department. Thus, the expansion and success of the Speedway had created a problem with the coordination of the many business functions.

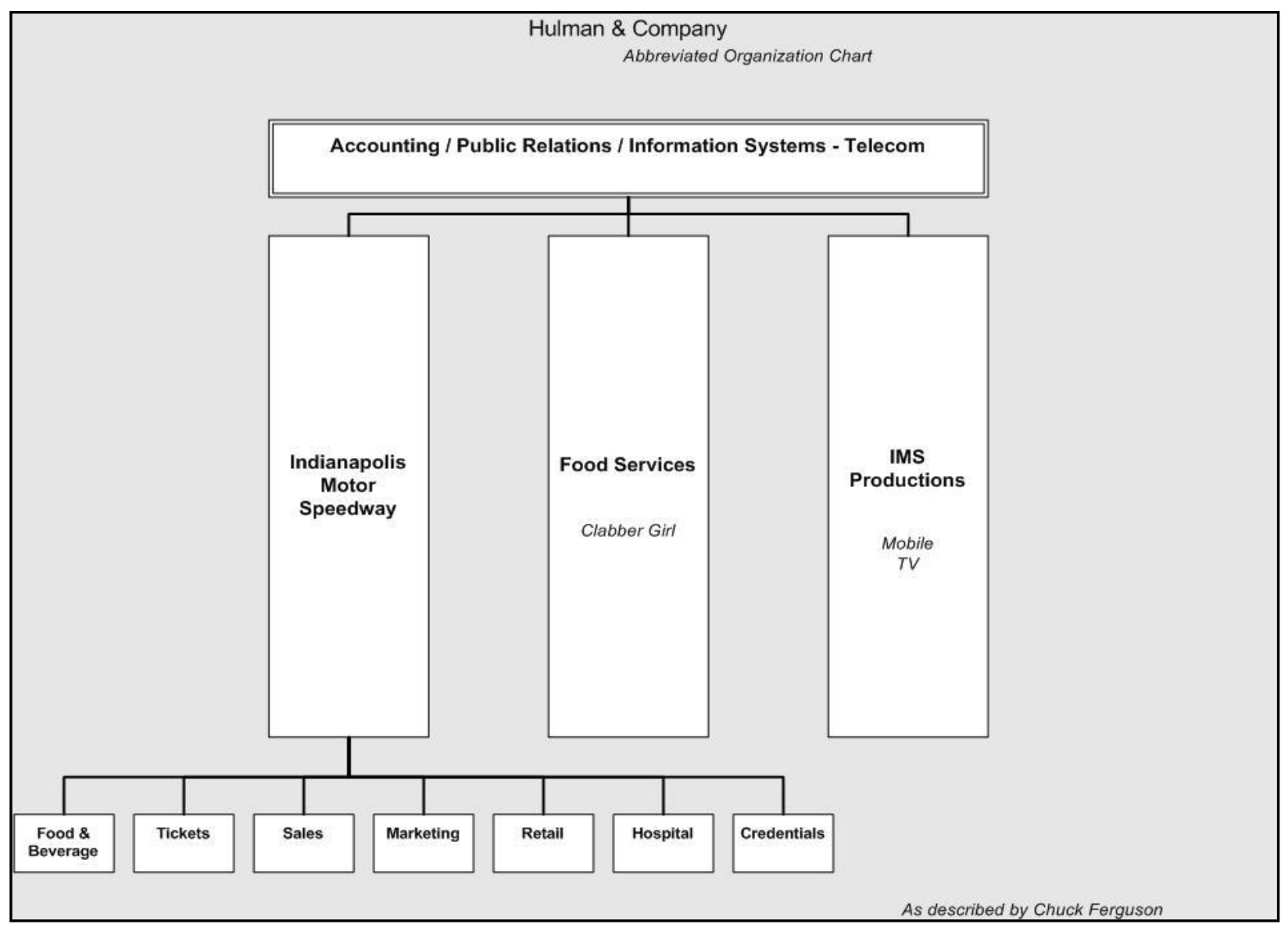

Figure 1 - Hulman and Company

\section{THE SOLUTION}

\section{Phase I: Database Integration and Enterprise Software.}

It was at this time in 2003 that Chuck Ferguson, Director of Information Systems and Telecommunications for Hulman \& Company, and Adrian Young, Director of Information Services, had started the migration of the multiple business databases to a single corporate database, an SQL Server database. This project was also tied to the implementation of enterprise software and the use of standard procedures across the organization. The core project team consisted of the IS staff, two representatives from Accounting, and consultants from Microsoft. All department heads were responsible for conversion and testing in the final stages. It was agreed that the business procedures would follow the standards of the accounting division in order to have uniform financial measurements. Adrian Young stated that this project was "all or nothing," that Phase I would be implemented across all operations of Hulman \& Company. Top management support for this project was absolute and unqualified. The project was successfully implemented within two years. Data clean-up extended beyond the two years, which is common in large-scale data integration projects, and was substantially completed within the following months. 
Before starting the project, the choice of enterprise software to utilize the single database was narrowed down to SAP or Microsoft Great Plains. After analyzing the features of the software and the business requirements of the Speedway, the IS staff chose to implement Great Plains, which was an upgrade from the previous developer's 5.5 version already installed to Microsoft's 7.5 version. In comparison, SAP is the leading developer of enterprise software and offers enhanced features and increased functionality over Microsoft GP. However, according to IS staff these features were more complex and extensive than what was required by the Speedway. Installing SAP would have increased the costs of the project due to size of the implementation required and the licensing fees. In addition to the software cost, the Microsoft software integrated easily with the other Microsoft applications already in use. This reduced the overall cost of the project by decreasing training, customization, and maintenance. Microsoft Great Plains was the best fit for the growing requirements of the organization, which was in need of improved financial reporting.

The greatest hurdle in this project was not the technical conversion, but rather the organizational change and project management required. Looking back, Chuck Ferguson suggested that detailed proposals from the vendor at the start of the project and the use of a smaller project team could have improved the speed of the integration. However, a speedier implementation would have compromised user buy-in. He stated that the key to any IS project is the ultimate buy-in from the end users. Since this project was driven by IT and Accounting, there was initial resentment from the other divisions of the organization due to the change demanded of these other business units. Great Plains is driven by best practices from accounting use in multiple industries, which ultimately required adjustments to successful business procedures of the Speedway. To work correctly, all these different procedures had to be merged into one standard view. This change was necessary to improve the overall financial reporting of the organization at the request of top management. The IMS had grown from a small company to a group of separate divisions with limited reporting links. This concept was not fully understood by the vendor and resulted in additional software customizing by the IS staff. The enterprise software was then able to begin coordinating the activities from the many functional areas of the Speedway.

The results of the data integration and enterprise software implementation were immediately noticeable. From an IT perspective, a great amount of time and effort has been saved by using a single database. This meant that there was only "one interface, one security system, and one version of software" to be maintained. No additional resources were required to collect and merge data from the different business lines. Time spent in the past on these manual tasks could now be directed towards data cleansing and implementing new IS projects such as CRM and SCORE. In addition, all the standard procedures approved by Accounting are documented in a SharePoint portal. This tool has since been expanded across the entire organization and is heavily used for the business requirement of Certificates of Insurance, necessary at the Speedway for all racing activity.

From a business perspective, one version of financial reporting has increased the effectiveness of the accounting department in supporting the other business units. IMS management could easily see the effect customers were having on different parts of the business. For example, it was stated that Kroger Supermarkets has a high volume of sales through the Speedway with tickets and merchandise, but also does business with Clabber Girl. Today, an executive for IMS can instantly access the impact on sales revenue that Kroger has across the business lines. In summary, IS has saved time and reduced costs by automating manual tasks and improving reporting, which will lead to sustainable new growth.

\section{Phase II: CRM \& Contract Management.}

The move to a single database allowed the IS staff to concentrate on projects to improve business unit performance. As stated earlier, the IMS is a unique organization focused on a high customer service level. After the installation of the enterprise software, Microsoft CRM was implemented to take advantage of the single database and to continue improving financial reporting within the company. This project was a logical step to leverage the Microsoft Office business applications that employees were familiar with, in addition to the Great Plains software. Microsoft CRM advertised features of improved communication tools, unified marketing and sales campaigns, realtime scheduling of services, and faster sales reporting. 
However, the business requirements of the Speedway were much different from a standard business and required extensive customization. The full implementation of Microsoft Great Plains, including CRM, required three years to complete. The software was "vanilla" out of the box and had to be customized to the needs of the functional areas at the Speedway tied to Sales, primarily focused on corporate customers. At the Speedway, all corporate sales are negotiated, and the sales contracts are not itemized. This process has always been an essential business requirement at the IMS, and it protects their relationship with corporate customers. According to Pat Hayes, the closest example in accounting terms would be a "personal services invoice." For example, most sales to a corporate customer (e.g., Kroger) are part of a package deal that could include tickets, merchandise, a hospitality suite, and a sponsorship award or trophy. These individual items are not priced out or itemized on the final contract, to prevent comparisons and providing leverage to the customer. As a result, the entire package deal is negotiated and would be classified, for example, as simply the "2007 Sponsorship Agreement." The ability to incorporate this standard IMS business process was a primary concern in the implementation of the CRM software, in order to protect these sensitive business requirements.

The final result of the CRM project installation has been increased coordination between the business units and improved decision-making by management. The software instantly allows IMS staff to view individual customer profiles, "what business they do with us," and "what business we do with them." For each corporate customer, a scorecard has been customized to provide financial comparisons and historical trends. According to Pat Hayes, a key component in the analysis of total sales is the allocation of "Pass-Through Dollars," a portion of sales that have no impact on the Speedway's bottom line, but have a substantial intangible effect on the organization. For example, Kroger Supermarkets may sponsor a trophy as part of their package deal. The sales dollars used to purchase this trophy have no impact on the Speedway's net income. The money is said to "pass through" the organization. This understanding of each contract's contribution has improved the decision-making process of Marketing and Sales towards allocation of limited resources towards their best customers. The president of the Indianapolis Motor Speedway has a "hot button" within the CRM application, which gives him instant access to the business generated by each corporate customer across the organization. This level of information provided by the CRM package, combined with real-time access, would not be possible without the implementation of a single database utilizing enterprise software. After expanding operations over the past decade, the organization is now able to continue increasing sales with the efficiency of a small company.

\section{Phase III: SCORE.}

The results of these recently implemented IS projects now allow the Indianapolis Motor Speedway to focus on the individual customers serviced by the Tickets business unit. According to Chuck Ferguson, they are "driving the customer base to the Internet." This in-house custom application is known as the SCORE project. SCORE is an acronym for "Sales focused, Customer centered, Online intensive, Rapid renewals, and Efficient \& effective." According to the project's vision statement, SCORE is "a sales oriented software application developed to integrate all major IMS automated processes including Customer Relationship Marketing, Ticketing, Credentialing, Marketing, and Accounting." The project will close the existing gaps between the business units that remain after the Great Plains/CRM implementation.

The goal is for SCORE is to improve the decision-making for all these units while improving coordination. For Tickets, it will reduce the renewal/upgrade processing cycle while making the division more focused on Internet sales. For Contract Management, SCORE will integrate the customized Microsoft CRM data with the Tickets business unit's FastTrax database. For Credentialing, it will provide coordination to improve process efficiency, automation, and control. For Marketing, SCORE will provide detailed analysis and reporting of the Speedway's individual customer base. Finally, for Accounting, the project will integrate all revenue channels for accurate and efficient financial reporting. This customization of new applications will be the challenge to the IS staff in order to maintain or exceed the current rate of organizational growth at the Speedway. 


\section{CONCLUSION}

According to Pat Hayes, the implementation of the customized CRM software has "unlimited benefits." The business units of the Speedway now have the ability to customize the information necessary to make detailed financial analysis and implement strategy according to their needs. The key success factor for this new growth was the data integration of the multiple lines of business at the Speedway. By obtaining one version of data, the business units can be better coordinated towards a higher service level with the use of enterprise software. The rapid growth of the organization had begun to stretch the capabilities of each functional area to a critical point. Investments in enterprise software, followed by development of CRM and SCORE, proved to be the solution to these developing problems. From these initiatives, the Indianapolis Motor Speedway is now in a position for improved financial performance and sustainable new growth.

\section{Discussion Questions}

1.) How can business-unit buy-in be attained during the development of the systems discussed in this case? How critical is end-user involvement in the successful implementation of systems such as the ones described in this case?

2.) Identify the key decisions that the Indianapolis Motor Speedway made to reduce the risk of failure in their implementation of enterprise software?

3.) How does CRM reduce costs and increase customer satisfaction at the Indianapolis Motor Speedway?

4.) Has IMS achieved its goal of aligning business strategy with its information systems?

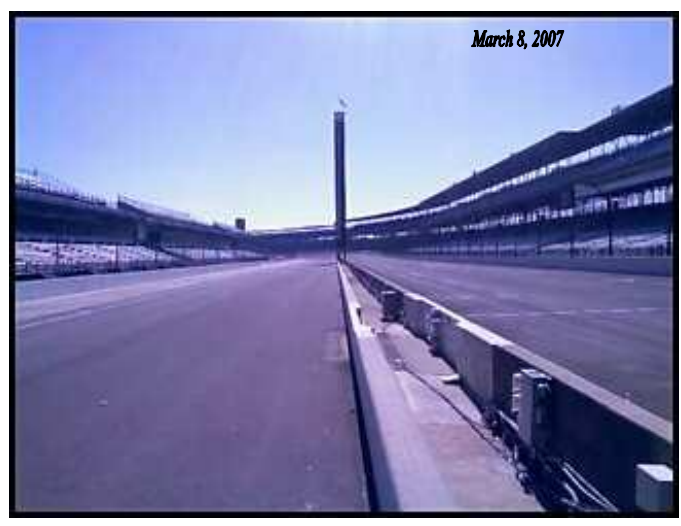

\section{THE INDIANAPOLIS MOTOR SPEEDWAY}

\section{INSTRUCTOR'S MANUAL}

\section{Objective}

This case study is a real-world example of aligning information systems with business strategy. The Indianapolis Motor Speedway is a unique organization with divisions that span from the racetrack to merchandising to a golf course. With a high service level as the foundation of their business strategy, the alignment of their information systems with their operational requirements is an excellent model for any business that competes by differentiation or is looking to reduce costs. In today's environment, correct decisions regarding information systems investment is necessary for continued success. 


\title{
Topical Coverage
}

This case study is intended to illustrate the issues surrounding planning and implementation of an enterprise system in a large organization with disparate business functions, with particular emphasis on application implementation, best practices, and IT investment decisions. It is recommended for either undergraduate- or graduate-level course work.

\begin{abstract}
This case study is a rare inside look at the business operations at the Indianapolis Motor Speedway. As part of a privately held company, the Speedway is a unique organization with functional areas that span from the racetrack to manufacturing to a golf course. Since the early 1990s, the business has experienced rapid growth due to the addition of two races (NASCAR and Formula One) and the creation of a separate racing league (Indy Racing League). However, this success was stretching the organizational framework that had been established for a single race event. The business units of the Speedway were being crippled because of multiple sources of data across the organization. With rapid growth, the functional areas had grown independent of each other to the point of isolation. This lack of communication and information sharing was inhibiting the Speedway from new growth and did not facilitate a high service level to their customers.

The solution to the problems being faced by the Speedway was an investment in information systems. The foundation of their recent business initiatives has been the consolidation of data from all the functional areas into one location. By centralizing and sharing data in combination with standard business procedures, the Speedway can better coordinate and report across the business lines for executive-level management. The quick wins from this data integration project and implementation of enterprise software have been improved customer relationship management and real-time communication between the multiple lines of business. The Speedway can now operate and coordinate their functional areas with the ease of a smaller company. Investment in information systems proved to be a key to the solution to these developing problems. From these initiatives, the Indianapolis Motor Speedway is now in a position for improved financial performance and sustainable new growth.
\end{abstract}

\section{Analysis}

An analysis of this case can begin with a SWOT analysis, as shown below. The case illustrates each of the strengths, weaknesses, opportunities, and threats perceived by the organization.

Indianapolis Motor Speedway - SWOT Analysis

\begin{tabular}{|c|c|}
\hline Strengths & Weaknesses \\
\hline $\begin{array}{c}\text { Facilities \& Staff } \\
\text { Information Services }\end{array}$ & E-Business \\
\hline Opportunities & Threats \\
\hline E-Commerce & Rising Costs \\
\hline
\end{tabular}

Key Issues: There are several key issues brought out by this case. Each is discussed below.

\section{Database Integration.}

By 2003, the Speedway was operating with ten business lines, each with their own database and financial procedures. Rapid growth had caused the business units to move further into isolation with limited communication. The use of multiple databases had led to problems with data integrity and data inconsistency, due to the unique 
customer entries for each functional area. Data inconsistency is defined as the presence of different values for the same attribute, when the same data are stored in multiple locations. In order to fulfill the reporting requests of top management, the IS staff had to manually compile data from multiple sources across the organization. The information systems in use at the Speedway were becoming more of a hindrance to operations rather than facilitating communication and decision-making. It was at this point that the IS staff implemented a project to merge the multiple databases into one corporate database.

The result of the data integration project was immediate improvements to the business operations at the Speedway. Data redundancy was eliminated due to one source of data. The IS staff no longer had to manually compile and merge multiple sources of data for organizational reporting. From their point of view, this infrastructure was easier to manage because there was "one interface, one security system, and one version of software to maintain." Time spent in the past on these manual tasks could be directed towards data cleansing and implementing new IS projects. Combined with enterprise software, the database integration established the foundation for further business improvements (Microsoft CRM and SCORE) at the Speedway. Correct data and management of information in the organization was the starting point for further IS-related development.

\section{Implementation of Enterprise Software.}

The integration of multiple databases into one corporate database facilitated the installation of enterprise software at the Speedway. Enterprise software is based upon the concept of increased coordination of business operations through organization-wide use of a standard software package. It incorporates modules for every functional area and business application to accomplish this goal. The choice of software for use at the Speedway was narrowed down to SAP or Microsoft Great Plains. SAP, the leading developer of enterprise software, offers enhanced features and increased functionality over Microsoft GP. However, Great Plains was easier to install and integrated easily with other Microsoft applications already in use. This reduced the overall cost of the project by reducing training, customization, and maintenance. In terms of manager decision-making, the best enterprise software for a company depends on its fit to the organization, rather than its popularity in the industry.

The greatest hurdle in any enterprise software implementation will be the organizational change required. This primarily involves standard business procedures being instituted across the multiple lines of business. The greater the buy-in from end users and support from executive-level management, the greater the chance for a successful implementation. At the Speedway, the use of accounting business procedures was supported by top management. This sent a clear signal towards movement in the change process. According to estimates, 40 to $60 \%$ of enterprise software implementations can be classified as failures on initial installation. As a business manager, it is important to understand the risks and success factors involved. If implemented correctly, enterprise software will increase coordination and reduce costs. If the project fails, then the organization can be weakened and face financial difficulties. It is recommended for successful implementation to make use of a phased approach.

\section{Customer Relationship Management driven by IS.}

The logical sequence of database integration, standard procedures, and implementation of enterprise software created the opportunity for CRM software to be introduced at the Speedway. The rapid growth at the track since the 1990's had begun to stretch the organization's framework for providing a high service level. For example, it was not uncommon for the IMS to double book hospitality suites to corporate customers, to be taken advantage for free promotions, and have unpaid customer accounts extended. The expansion and success of the Speedway had created a problem with the coordination of the many business functions. The use of CRM software made it possible to improve the Speedway's customer focus across the organization through real-time information access.

The key driver to executing CRM techniques effectively is through information systems and applications. Customer information and the organization's technology tools are the foundation elements for a successful CRM strategy. Information technology can automate the capture of knowledge, enable customer communication channels, and collect feedback for analysis. CRM software is designed to capture and integrate customer data from all functional areas of the organization for consolidation, analysis, and distribution. For the Speedway, the 
implementation of CRM software required additional customization due to unique business procedures. A key business requirement at the Speedway was that all corporate sales are negotiated and sales contracts were not itemized. In terms of management decision-making, the cost of implementing CRM-related software must consider the customization requirements for the organization.

\section{Alignment of Business Strategy and Information Systems.}

Executing business strategy in today's environment requires the close coordination of information systems and technologies. The four dimensions that influence alignment are business unit strategy, level of product customization, level of process customization, and volume of customers. As a business manager, the choices made for software and the investment of information systems need to factor in these four dimensions. A key factor in the case study was the process customization of the CRM software to the business needs of the Speedway. Customizing software can significantly influence competitive performance for companies focused on differentiation. In contrast, extensive customization of software would not be in alignment, in most cases, with a low-cost producer business model.

\section{Database Integration.}

The concept of data integration is based on compiling different data sources into a central database or by sharing it between systems. One desired result of data integration is the elimination of data redundancy. Data redundancy is the presence of duplicate data in multiple data files, which results in the same data being stored in multiple locations. This redundancy occurs in an organization due to different divisions, functional areas, or groups collecting the same data and storing it independently. Data redundancy often leads to data inconsistency for the organization. Data inconsistency is the presence of different values for the same attribute, when the same data are stored in multiple locations. Data integration solves this inconsistency problem by storing a single value for each attribute in a shared location.

Data inconsistency is a common problem in mature organizations due to rapid growth and expansion of operations. The root cause of data redundancy is the organizing of data in the traditional file environment. The traditional method called for the development of specialized applications requiring unique data files. The lack of a central data source results in program-data dependence, which is the coupling of data to specific programs. With time, these information systems grow independently and move further into isolation from other functional areas in the company. It is not uncommon for the areas of accounting, finance, manufacturing, human resources, and sales to each have individual systems and data files. This results in multiple master files being created, maintained, and accessed for processing. In a short period of time, the organization will suffer significant costs due to the time and resources that need to be allocated to maintain a growing list of programs and applications. If managed poorly, the organization will encounter data inconsistency, poor data security, program-data dependence, inflexibility, and the inability to share data among applications. These problems will increase the organization's costs of doing business and will hinder decision-making, instead of enhancing the process (Laudon and Laudon, 2006).

Database technology solves the problems caused by a traditional file organization. A database can serve multiple applications by collecting data into a central location. The key component of this infrastructure is the database management system (DBMS). The DBMS is the software that manages the creation, storage, retrieval, and manipulation of the enterprise's data, information, and knowledge. A DBMS eliminates the data definition statements that traditional programs required linking size, format, and location of each data element for execution. This is achieved by separating the logical and physical views of the data, making the actual database available for different logical views presented for various application programs. The database management system acts as the interface between the application programs and the data. As such, the DBMS is the key enabling technology for business and has become an indispensable tool for the efficient and effective operation of the modern enterprise (Hoven, 2002). 


\section{Database Implementation.}

Successful implementation of a database requires the collaborative effort of the entire organization. At the start of a data integration project, it is necessary to identify the users of the database, their organizational tasks, and the database usage. As a business manager, the criteria for measuring the success of the project must be analyzed from the end user perspective when estimating costs. User satisfaction is dependent on the system factors of data quality, ease of data query, and system throughput. Research shows that the main users of the system will be firstline (or lower) and middle managers. System design and management issues in the organization must be addressed during the early stages of the project, in order to optimize the database as an effective decision support environment. For example, in the IMS case story, it was critical that standard procedures for the entire organization were established early in the project. By using accounting's procedures as standard, the Speedway improved the effectiveness of the database by having common specifications for financial measurements.

Establishing a central database for your organization is not an automatic guarantee of cost savings and improved decision-making. A common assumption is that if a database is created, then business units will find a use for it. In practice, it has been reported that $60 \%$ of companies rate their data management system as having limited success in terms of user expectations. A critical barrier is user resistance. The reasons cited for this behavior can be attributed to the fear of losing control, lack of technical skills, overall costs, and uncertainty about its utility. In general, user resistance can be overcome by increasing their involvement and input on design early into the project. In the case, the department heads of each of the Speedway's functional areas were responsible for conversion and testing. Upper management support in the IMS project was a clear signal of the organization's goals and facilitated movement. Without top management commitment, most information systems projects will result in failure. Due to the investment and resources required for centralizing data, a thorough evaluation of the project's values, risks, and return-on-investment should be conducted (Shin, 2003).

Once the project has been commissioned, the implementation process will involve the merging of technology and social issues. Successful projects have cited user champions, access to a wide range of data, and flexible user tools as keys to improved return-on-investment. Not all users will access the database in the same manner. Some users will prefer simple and direct tools for a narrow range of data. In contrast, another group of users will demand unrestrictive access in order to create personal ad hoc queries and reports. By considering flexibility through the implementation process, users' rating of success will be increased. Through industry interviews, seven intervention points have been identified as keys to preventing failure:

Initiation Phase:

1. Does top management support the database?

2. Do users support the database?

Design Phase:

3. Do users want access to a broad range of data?

4. Do users want limited data access and analysis tools?

Training Phase:

5. $\quad$ Do users understand the task fit?

6. Do users perceive IT as supportive?

7. Does the business unit have one or more power users?

These intervention points can assist in understanding the human factors and the technology requirements for improved implementation. Due to the high costs associated with database integration, it is necessary to avoid the one-dimensional approach in order to ensure value is delivered (Chenoweth, Corral, and Demirkan, 2006). 


\section{Enterprise software.}

Enterprise software is defined as "a set of integrated modules for applications such as sales and distribution, financial accounting, investment management, materials management, production planning, plant maintenance, and human resources that allows data to be used by multiple functions and business processes" (Laudon and Laudon, 2006). To work, these systems are designed around thousands of predefined business processes. The key driver of enterprise software is a common central database. The database provides data collection and feeds the data to multiple applications that can support the majority of an organization's internal business activities. When new information is entered by one functional area, the information is available in real-time to all other business processes. The desired result of implementing enterprise software is the integration of the organization's information and business processes to improve efficiency.

In order to facilitate the numerous business activities of an organization, enterprise software spans the boundaries of internal and external operations. It is designed to utilize thousands of process maps. Each process map is a reference model that follows the manual steps necessary to complete a business objective. For example, the software would automate the process between the functional areas of an organization for a purchase order. Enterprise software is a term for applications that include enterprise resource planning (ERP), customer relationship management (CRM), and supply chain management (SCM). Initially designed as a client/server application for private networks, most enterprise software applications have moved to the Internet. The Internet provides a low cost, standard communication link that can be accessed through a common Web browser. Enterprise software can now remove the logistical barriers between internal and external operation coordination (Laudon and Laudon, 2006).

Cost savings and improved decision-making for the organization are the stated goals of using software to facilitate process integration. The single information architecture and the standardization of business processes creates a platform for organization-wide coordination. It allows for a more uniform organization, increased efficiency in operations, customer-driven business processes, and firm wide information. The organization structure can be "flattened" from the traditional pyramid structure due to the elimination of middle managers, responsible for physically coordinating executive-level strategy and operations. With increased communications, business units worldwide can operate with a more uniform corporate culture. By having all functional areas use the same software, the organization is better equipped to react to customer demands due to the integration of discrete business processes.

The decision to implement enterprise software in an organization will involve a high demand on large groups of people and will mark a change in culture. The greatest hurdle will be the actual social integration of all functional areas. Most organizations are an umbrella of separate business units, which tend to operate in near isolation. At the start of this type of project, the use of standard business procedures must be implemented across the organization. In the case story, the IMS chose to follow the standard procedures used by accounting, in order to have common financial measurements. This act forced all other divisions of the Speedway to adopt different procedures and was met with initial resistance. This hurdle was overcome primarily due to top management support. Meeting this objective ensured the success of the project and will also help the Speedway operate as a more uniform organization when facing future change.

After implementing standard business procedures, the next step is to install the enterprise software. This is a complex project due the need for identifying the many business processes for automation and mapping these steps to the application. For example, SAP has more than 3,000 configuration tables available for customizing. This complexity is the reason for the high failure rate of most ERP projects. It is estimated that 40 to $60 \%$ of ERP implementations can be classified as failed projects. As a business manager, this risk must be weighed and analyzed before purchase due to the high costs. In order to achieve maximum return-on-investment, an organization-wide commitment must be agreed upon. It is recommended that a company-wide ROI be calculated, and further ROI estimates placed at the division, functional, and ERP module levels (Liang, et al., 2007). Failure to implement enterprise software can weaken an organization and lead to financial difficulties. 
In the case story, the primary reason that the Speedway chose Microsoft Great Plains over SAP was its ease of use. Ease of use is the key element to user satisfaction and will lead to additional cost savings after implementation. The Great Plains software integrated easily with the suite of Microsoft applications (primarily MS Word and Excel) that were already installed and used commonly by end-users. The selection of enterprise software is a critical decision that must match the business requirements of the organization. There is no one "best" enterprise software application on the market for purchase. It is recommended for business managers to investigate the reported successful and failed implementations that are available in industry publications. Vendors can also provide contact to managers of companies that have previously installed the software.

The implementation of enterprise software should be a phased approach (Sardoni, 2002). The sequence of projects at the Speedway involved the upgrade of Microsoft Great Plains ERP software followed by Microsoft CRM software. These two projects were not implemented at the same time. After each phase, ROI should be evaluated before moving to the next stage. If the software does not meet the business needs, a decision must be made to continue the project with input from top management. During the entire implementation process, it is recommended that the organization resist customizing the ERP software, which would increase the costs of the project. The new application should not be a mirror of past business practices. The key driver of the software is the optimizing business processes based on best practices. Implemented correctly, enterprise software can provide the increased cost savings and better efficiency required in a rapidly changing business environment.

\section{8. $\quad$ Customer relationship management.}

Customer relationship management (CRM) can be defined as "an integrated strategic approach to capture a disproportionately high share of value from current and potential customers by using proprietary customer information effectively" (Ling and Yen, 2001). The overall goal is to enhance customer value through a better understanding of individual customer needs and preferences. In the past, customer evaluation was the responsibility of sales and marketing or the customer service department. The foundation of CRM is based on making the customer the focus of the entire organization and of each functional area. The desired result of this business strategy is to strengthen the customer's relationship with the organization as a long-term focus and to maximize the customer's profitability for the company. Instead of treating all customers equally, it is more profitable to invest in customers that are valuable or potentially valuable, while limiting resources spent on non-valuable customers (Cunningham, et al., 2006). Every business can divide their customer base into four value-strategy segments:

1. to invest ;

2. to engage;

3. to re-engineer ;

4. or, to eliminate (Ling and Yen, 2001).

Customers that should be eliminated or re-engineered have a historically low value to the organization. Because resources are limited for every organization, it is critical to maximize return-on-investment due to increasing competition and rising costs.

The solution to executing CRM techniques effectively is through information systems and applications. Customer information and the organization's technology tools are the foundation elements for a successful CRM strategy. Information technology can automate the capture of knowledge, enable customer communication channels, and collect feedback for analysis (Ling and Yen, 2001). In the current business environment, customers are seeking more access and easier interaction with the organization. Most customers now prefer to use the Internet due to the richness of information available and the lowering of search costs. Every organization that utilizes the Web has increased customer reach and can use the same technology to market to individual customers. CRM software integrates these channels of interaction and helps build customer loyalty with these sophisticated customers through one-to-one marketing. CRM strategy dictates that there are only three ways to increase profitability of the customer base: acquire more customers, optimize the value of existing customers, or retain the profitable customers longer (Cunningham, et al., 2006). 


\section{CRM Implementation.}

Similar to the implementation of enterprise software, CRM software installation requires a thorough evaluation of current business practices. Organizational issues must be addressed in order for human interaction with the system to be fully utilized. Industry surveys show that 50 to $80 \%$ of CRM initiatives fail due to inappropriate or incomplete processes and the poor selection of technologies. ${ }^{1}$ In response, four key elements have been identified as critical to successful implementation. This framework includes:

1. a readiness assessment;

2. change management review;

3. project management review; and

4. employee engagement (Payne and Frow, 2006).

The readiness assessment helps business managers understand the scope of the project and which business processes need concentration. The presentation of the audit results to top management will also facilitate understanding and buy-in at the early stage. Change management is associated with identifying the key skills gaps that are required for success. Senior management sponsorship, creation of a CRM vision, and the use of crossfunctional teams will eliminate the majority of change management issues that arise. Project management is essential to ensure CRM credibility. This consists of clearly defining objectives, goals, and ROI outcomes of each stage of the implementation. Most important, employee engagement should be the starting point for all CRM activities. In the case study, the working relationship between Pat Hayes and the IS staff was critical for customizing the generic CRM software to the business requirements of the Speedway.

The key enabling technology that permits an extensive customer relationship management strategy is the database or data warehouse. The database is necessary for storing and accessing customer data to execute the oneto-one marketing plan. The information collected can be classified into two categories: operational data and marketing information (Francese and Renaghan, 1990). Operational data is represented by customer identities such as name, title, company name, address, and payment methods. Marketing information in the database is centered on customer preferences. Customer preferences include history, frequency, and responses to promotions. The design of the database needs to consider the special requirements of each business. For example, in order for the CRM software at the Speedway to be effective, the customer information had to be available in real-time for sales activities, and the distinction between "pass-through dollars" and actual revenue contribution on each sale needed to be identified in the database. Understanding how the business users will access the database is the first step for successful CRM implementation.

A customer relationship management strategy will greatly increase the demands on the information systems and technology of the organization. In most cases, the software applications will need to be customized to tailor the unique business processes. In the case study, many of the features of the Microsoft CRM software used at the Speedway had to be further developed for the business operations. A key factor in the success of the CRM implementation at the IMS was that it was applied to the corporate customers before the individual customers. By starting with the smaller and relatively more important customer base, the design and customization of the software was easier to manage for the staff and the end-users. Dividing the implementation project by customer requirements reduced the scale of the project and provided for a better estimate for return-on-investment.

\section{IS and Business Strategy Alignment.}

Business strategy is the "set of activities and decisions that determines the products and services the firm produces, the industries in which the firm competes, firm competitors, suppliers, and customers, and the firm's longterm goals." ${ }^{2}$ In order to sustain competitive advantage, the firm must create an alignment between their operations and strategy. Alignment is the key factor for accomplishing strategic goals because individual activities inside the firm can influence each other that either strengthen or weaken the position of the organization. ${ }^{3}$ Executing business strategy in today's environment requires the close coordination of information systems and technologies. An organization's investment in information systems will have a direct relationship with their ability to meet short-term 
goals (5 years or less). For long-term goals, information technology will influence the firm's primary and secondary activities, which add a margin of value to the product or service.

There are four dimensions that influence alignment:

1. the business unit strategy;

2. the level of product customization;

3. the level of process customization; and

4. the volume of customers (Laudon and Laudon, 2006).

Business managers should factor these four dimensions into the choices made for software and investment of information systems. A key factor in the case study was the process customization of the CRM software to the business needs of the Speedway. Customizing software can significantly influence competitive performance. The degree of software customization and information system investment for an organization will depend on the business strategy. The events held at the Indianapolis Motor Speedway are the largest gathering of spectators in racing and the race events are an excellent example of differentiation. By aligning strategy and investment in information technology, the IMS has achieved increased financial performance and positioned the organization to adapt to greater change.

\section{Suggested Answers To Discussion Questions}

1.) How can business-unit buy-in be attained during the development of the systems discussed in this case? How critical is end-user involvement in the successful implementation of systems such as the ones described in this case?

The success of any information systems project will ultimately be judged from the end-user perspective. In most cases, successful implementation requires the collaborative effort of the entire organization. At the beginning of an IS project, it is necessary to identify the users of the system, their organizational tasks, and the usage of the system. At the Speedway, the implementation of the enterprise software required the use of standard financial procedures across the organization before installation. This business requirement was supported by top management, which sent a clear signal for movement towards this overall goal. The leaders of each department were also responsible for final testing and conversion. Without executive-level commitment, most projects will fail due to a loss of belief in the effectiveness of the application. The next step is user buy-in for the system. The best way to create this atmosphere in the organization is to involve users in the design and implementation of the project. Ownership in the project greatly increases user buy-in. This reduces the risk of a failed project, the overall cost of implementation, training expenses, and uncertainty about its utility.

\section{2.) Identify the key decisions that the Indianapolis Motor Speedway made to reduce the risk of failure in their implementation of enterprise software?}

The greatest hurdle in the implementation of enterprise software is the actual social integration of all the functional areas. This hurdle places a high demand on large groups of people and will require a change in the culture. At the Speedway, key decisions were made early in the project that reduced the risk of failure. First, top management commitment in the project was achieved before the start of implementation. This commitment sent a clear signal to the organization of the belief in the effectiveness of the application. Second, standard business procedures used by Accounting were implemented across the business units of the organization. To maximize the usefulness of enterprise software, standard procedures are necessary to increase business line coordination. Meeting this objective increased the likelihood of the success of the project and also helped the Speedway operate as a more uniform organization when facing future change. Third, the scope of the project was implemented in a phased approach. The IS staff did not implement Great Plains and Microsoft CRM at the same time. This approach allowed for better project management and estimates of costs to be closer. Last, the IS staff's choice of enterprise software was based on the best fit to the organization. Instead of choosing the industry standard, the Speedway 
implemented the software that would integrate easiest with existing applications. Ease of use is the key element to user satisfaction and will lead to additional cost savings (training and maintenance) after implementation.

\section{3.) How does CRM reduce costs and increase customer satisfaction at the Indianapolis Motor Speedway?}

The Microsoft CRM software installed at the Speedway has increased coordination between the business units and improved decision-making by management. As a business manager, it must be recognized that every organization has limited resources which must be allocated appropriately to maximize the return on investment. Prior to implementation, the framework of the organization was being stretched to provide a high service level in the face of increased growth. Within Pat Hayes' department and necessitated by Sales and Marketing, the added issue of communication and coordination was restricting service to customers. It was not uncommon for the IMS to double-book hospitality suites to corporate customers, to have unpaid customer accounts extended, and to have free promotions distributed multiple times to the same customer. The final result of the CRM project installation has been increased coordination between the business units and improved decision-making by management. The software instantly allows IMS staff to view individual customer profiles, "what business they do with us," and "what business we do with them." After expanding operations over the past decade, the organization is now able to continue increasing sales with the efficiency of a small company.

\section{4.) Has IMS achieved its goal of aligning business strategy with its information systems?}

Alignment is the key factor for accomplishing strategic goals because individual activities inside the firm can influence each other that either strengthen or weaken the position of the organization. Executing business strategy in today's environment requires the close coordination of information systems and technologies. An organization's investment in information systems will have a direct relationship with its ability to meet short-term goals (5 years or less). For long-term goals, information technology will influence the firm's primary and secondary activities, which add a margin of value to the product or service. There are four dimensions that influence alignment: the business unit strategy, the level of product customization, the level of process customization, and the volume of customers. As a business manager, the choices made for software and investment of information systems need to factor these four dimensions. The events held at the Indianapolis Motor Speedway are the largest gathering of spectators in racing and are an excellent example of differentiation. By aligning strategy with their level of investment in information technology, the IMS has achieved increased financial performance and positioned the organization to adapt to greater change.

\section{REFERENCES}

1. Chenoweth, T., Corral, K., and Demirkan, H. "Seven Key Interventions for Data Warehouse Success," Communications of the ACM, Vol 49, Iss. 1 (January 2006).

2. Cunningham, C., Song, I, and Chen, P. "Data Warehouse Design to Support Customer Relationship Management Analyses," Journal of Database Management, Vol. 17, Iss. 2 (April-June, 2006).

3. "History of the Indianapolis Speedway," Wikipedia, March 1, 2008, <http://en.wikipedia.org/wiki/indianapolis_motor_speedway>

4. Hoven, J. “Adding Value to Data,” Information Systems Management, Summer 2002.

5. "Indianapolis 500," Wikipedia, March 1, 2008, <http://en.wikipedia.org/wiki/indianapolis_motor_500>

6. Laudon, K. and Laudon, J. Management Information Systems: Managing the Digital Firm, $9^{\text {th }}$ Ed. New jersey: Pearson Prentice Hall, 2006.

7. Liang, H. Saraf, N., Hu, Q. and Xue, Y. "Assimilation of Enterprise Systems: The Effect of Institutional Pressures and the Mediating Role of Top Management," MIS Quarterly, Vol 31, Iss. 1 (March 2007).

8. Ling, R and Yen, D. "Customer Relationship Management: An Analysis Framework and Implementation Strategies," Journal of Computer Information Systems, Vol.41, Iss. 3 (Spring 2001).

9. Payne, A. and Frow, P. "Customer Relationship Management: From Strategy to Implementation,” Journal of Marketing Management, Vol. 22, (2006). 
10. Sardoni, K. "Enterprise Software: Reaping the Rewards and Avoiding the Traps," Enterprise/Salt Lake City, Vol. 32, Iss. 19 (Nov. 4, 2002).

11. Shin, B. "An Exploratory Investigation of System Success Factors in Data Warehousing," Journal of the Association for Information Systems, Vol. 4, 2003.

12. Slaughter, S., Levine, L., Ramesh, B., and Pries-Heje, J. “Aligning Software Processes with Strategy,” MIS Quarterly, Vol 30, Iss. 4 (December 2006).

13. "The Hulman Family," The Indianapolis Star - IndyStar.com. April 13, 2008 〈http://www2.indystar.com/library/factfiles/sports/autoracing/indy500.html>

\section{NOTES}

